alpha inhibitor (TNFa -i) treatment in AS patients (1), no data is available for secukinumab.

Objectives: To evaluate the effect of obesity on the treatment response and drug survival of secukinumab in patients with axSpA.

Methods: We performed an observational cohort study based on the TURKBIO between 2018-2020. A total of 185 patients were included in the study. The patients were divided into three groups as obese $\left(B M l \geq 30 \mathrm{~kg} / \mathrm{m}^{2}\right)$, overweight (BMI:25-30 kg/m ${ }^{2}$ ), and normal $\left(B M l<25 \mathrm{~kg} / \mathrm{m}^{2}\right)$. Disease activity was evaluated at baseline and 3, 6 and 12 months of secukinumab therapy. Clinical response was evaluated as achievement of BASDAI50, ASAS20/40, and ASDAS-Clinical and improvement (CII and $\mathrm{MI}$ ) rates.

Results: 185 axSpA patients were identified in the registry; 135 (72\%) had available BMI data. Thirty nine (28.8\%) patients were obese. The mean age of obese patients was higher $(p=0.002)$. The frequency of HLA-B27 and male gender was lower in obese group ( $p=0.012$ and $p=0.013$, respectively). There was no significant difference between groups in terms of clinical response parameters at 3 , 6 and 12 months (Table 1). Drug retention rates were higher in biologic naive patients $(p=0.007)$ (Figure 1).
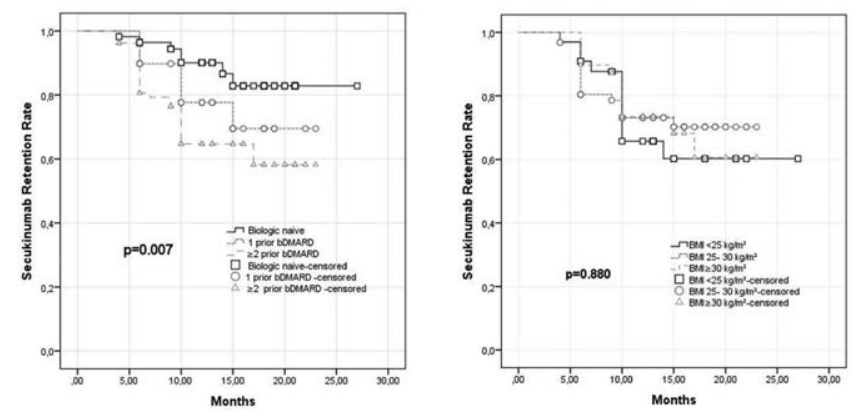

Figure 1

Conclusion: This study demonstrated that obesity had no impact on the efficacy and retention of secukinumab treatment in patients diagnosed with axSpA. The drug survival was found to be higher among biologic-naive axSpA patients compared to biologic-experienced.

References:

[1] Ottaviani S.et al. "Body mass index influences the response to infliximab in ankylosing spondylitis",Arthritis Res Ther 2012; 14: R11

Disclosure of Interests: None declared

DOI: 10.1136/annrheumdis-2020-eular.3961

\section{THU0391 THE INFLUENCE OF OBESITY ON TREATMENT RESPONSE TO BIOLOGIC AGENTS IN ANKYLOSING SPONDYLITIS}

J. H. Kim ${ }^{1}$, G. Y. Ahn ${ }^{1}$, J. H. Jung ${ }^{1}$, S. J. Choi ${ }^{1}$, G. G. Song ${ }^{1} .{ }^{1}$ Korea University College of Medicine, Internal medicine, Division of Rheumatology, Seoul, Korea, Rep. of (South Korea)

Background: Obesity can be a factor that affects response to tumor necrosis factor inhibitors (TNFi). Few studies have investigated the impact of obesity on the response to TNFi in patients with ankylosing spondylitis (AS).

Objectives: The aim of our study was to investigate the impact of different body mass index (BMI) categories on TNFi response in patients with AS.

Methods: Patients with AS from the Korean College of Rheumatology Biologics (KOBIO) registry were included in the current study. Patients who started a first TNFi after recruitment, and had available BMI data as well as a baseline and follow-up visit at 1 year ( \pm 6 months) were included. Patients with a BMI $<18.5$ were excluded. Patients were categorized according to BMI: normal (BMI 18.5 to $<25$ ), overweight (BMI 25-30), and obese (BMI >30). We evaluated the proportion of patients achieving the $40 \%$ improvement in ASAS criteria (ASAS40), as well as Ankylosing Spondylitis Disease Activity Score (ASDAS) improvement status at 1 year.

Results: A total of 1003 AS patients starting a first TNFi were considered in the current study (696 patients of normal weight, 267 patients with overweight, and 40 obese patients). After at 1 year follow-up visit, obese individuals were significantly higher ASDAS-CRP levels but were not significantly lower ASDAS major improvement in comparison to patients of normal weight.

Conclusion: Obesity is associated with significantly higher ASDAS-CRP at follow-up visit in patients with AS.

Disclosure of Interests: None declared

DOI: 10.1136/annrheumdis-2020-eular.5340

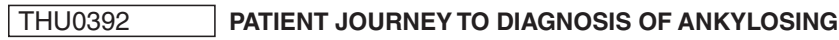 SPONDYLITIS AND ITS TREATMENT PATTERNS ACROSS CENTRAL EASTERN EUROPE ANDTHE UNITED STATES}

T. Korotaeva ${ }^{1}$, O. Dina ${ }^{2}$, E. Holdsworth ${ }^{3}$, L. Fallon ${ }^{4}$, G. Milligan ${ }^{3}$, S. Meakin ${ }^{3}$, L. Wang ${ }^{5}$, R. S. Vasilescu ${ }^{6}$, J. C. Cappelleri ${ }^{5}$, A. Deodhar ${ }^{7} .{ }^{1}$ Institute of Rheumatology, Moscow, Russian Federation; ${ }^{2}$ Pfizer Inc, New York, United States of America; ${ }^{3}$ Adelphi Real World, Bollington, United Kingdom; ${ }^{4}$ Pfizer Inc, Montreal, Canada; ${ }^{5}$ Pfizer Inc, Groton, United States of America; ${ }^{6}$ Pfizer Inc, Brussels, Belgium; ${ }^{7}$ Oregon Health \& Science University, Portland, United States of America

Background: Long delays in the diagnosis of ankylosing spondylitis (AS) and in receiving advanced therapies signify a critical unmet need. Little is known about delays or treatment patterns in Central Eastern European (CEE) countries.

Objectives: To describe patient time to diagnosis of and its treatment patterns in CEE and the US.

Methods: Data were collected via a cross-sectional survey of rheumatologists in Czech Republic, Poland, Russia, Ukraine (Sept-Dec 2019) and US (Jun-Aug 2018) via physician-completed patient record forms. In consecutive patients with a physician-reported diagnosis of AS, rheumatologists recorded patient demographics, clinical features, time to first consultation and diagnosis and treatment history. Data were compared for CEE vs US using t-test for independent samples (continuous outcomes) and Fisher's exact test (categorical outcomes). Low rates of HLA-B27 and sacroilitis at diagnosis may reflect combining non-radiographic axial spondyloarthritis under the diagnosis of AS in real-world practice.

Results: 209 physicians (121 CEE; 88 US) provided data for 1363 patients (876 CEE; 487 US). While some demographic differences existed between regions, estimated prevalence of HLA-B27 in patients with AS was the same between US and CEE. Not all patients were stated to have sacroilitis at diagnosis (Table 1). Time to first consultation and time to diagnosis were longer in CEE, with more patients experiencing a delay due to another condition initially being diagnosed (Table 2). At diagnosis a similar proportion of patients in CEE and US were prescribed NSAIDs, with higher use of csDMARDs in CEE. bDMARDs were more commonly prescribed at diagnosis in the US, with increased usage continuing after diagnosis (Figure 1).

Table 1. Patient demographic and clinical characteristics

\begin{tabular}{|c|c|c|c|}
\hline & $\begin{array}{c}\text { CEE } \\
(n=876)\end{array}$ & $\begin{array}{c}\text { US } \\
(n=487)\end{array}$ & P value* \\
\hline \multicolumn{4}{|l|}{ Demographic characteristics } \\
\hline Age, mean (SD) & $45.4(12.7)$ & $46.4(14.1)$ & $0.21(\mathrm{TT})$ \\
\hline Male, $\mathrm{n}(\%)$ & $6319(72.0)$ & $344(70.6)$ & $0.62(\mathrm{FE})$ \\
\hline BMI, mean (SD) & $25.9(4.1)$ & $27.4(4.5)$ & $<0.01$ (TT) \\
\hline Full time employment, $\mathrm{n}(\%)$ & 460 (53.9) & $342(70.8)$ & $<0.01$ (FE) \\
\hline Caucasian, $\mathrm{n}(\%)$ & $853(97.4)$ & $393(80.7)$ & $<0.01(\mathrm{FE})$ \\
\hline \multicolumn{4}{|l|}{ Clinical features at diagnosis } \\
\hline HLA-B27 positive, n (\%) & $592(67.6)$ & $329(67.6)$ & $1.00(\mathrm{FE})$ \\
\hline Inflammatory back pain, $\mathrm{n}(\%)$ & $712(82.0)$ & $369(76.7)$ & 0.02 (FE) \\
\hline Sacroiliitis identified by X-ray, n (\%) & $598(68.9)$ & $272(56.5)$ & $<0.01(\mathrm{FE})$ \\
\hline Back pain >3 months, $\mathrm{n}(\%)$ & 427 (49.2) & $225(46.8)$ & 0.46 (FE) \\
\hline Physician perceived severity, $\mathrm{n}(\%)$ & & & 0.02 (FE) \\
\hline - Mild & $69(8.7)$ & $20(5.1)$ & \\
\hline - Moderate & $414(52.1)$ & $233(59.1)$ & \\
\hline - Severe & $312(39.2)$ & $141(35.8)$ & \\
\hline
\end{tabular}

*Statistical test legend: TT=t-test; FE=Fisher's Exact.

Table 2. Patient diagnosis journey

\begin{tabular}{|c|c|c|c|}
\hline & $\begin{array}{c}\text { CEE } \\
(n=876)\end{array}$ & $\begin{array}{c}\text { US } \\
(n=487)\end{array}$ & P value* \\
\hline $\begin{array}{l}\text { Time from first symptoms to first consultation }{ }^{\alpha} \text {, } \\
\text { mean months (SD) }\end{array}$ & $27.7(53.7)$ & $18.5(57.1)$ & $0.02(\mathrm{TT})$ \\
\hline $\begin{array}{l}\text { Time from first consultation }{ }^{\alpha} \text { to diagnosis, mean } \\
\text { months (SD) }\end{array}$ & $17.8(48.6)$ & $6.0(13.2)$ & $0.02(\mathrm{TT})$ \\
\hline \multicolumn{4}{|l|}{ Reasons for delay ${ }^{\beta}, \mathrm{n}(\%)$} \\
\hline - Other condition initially diagnosed & $108(33.3)$ & $9(11.8)$ & $<0.01(\mathrm{FE})$ \\
\hline - Waiting for referral to correct $\mathrm{HCP}$ & $69(21.3)$ & $22(28.9)$ & 0.17 (FE) \\
\hline - Needed test conducting to confirm diagnosis & $100(30.9)$ & $21(27.6)$ & 0.68 (FE) \\
\hline
\end{tabular}

*Statistical test legend: TT=t-test; FE=Fisher's exact; ${ }^{a}$ First consultation with any healthcare professional about AS symptoms; ${ }^{\beta}$ Delay defined as $>3$ months from first consultation to diagnosis.

Conclusion: Time to diagnosis was three times longer in CEE vs the US. Despite similar prescription of NSAIDs at diagnosis in US and CEE, a greater proportion of patients currently received NSAIDs and csDMARDs in CEE, while bDMARD use in the US was greater. This suggests different treatment approaches and differences in medication access across the regions. 